\title{
Association between somatostatin levels and life of polymorphonuclear neutrophils in macaques following intestinal ischemia-reperfusion
}

\author{
Lan-tao Xu', Yan-yan $\mathrm{Wu}^{1}$, Hua Fan ${ }^{2}$, Qing-hua $\mathrm{Tan}^{2}$, Bing $\mathrm{Hu}^{2}$, Chun-hui Wang ${ }^{2}$ and \\ Cheng-wei Tang ${ }^{2 *}$
}
${ }^{1}$ Department of Gastroenterology, Fengxian Branch of 6th Hospital, Shanghai Jiao Tong University School of Medicine, Shanghai 201400, P. R. China.
${ }^{2}$ Division of Peptides Related with Human Diseases, State Key Laboratory of Biotherapy of Human Diseases, West China Hospital, Sichuan University, Chengdu 610041, P. R. China.

\section{Accepted 21 April, 2011}

\begin{abstract}
Previous studies have shown that delayed apoptotic polymorphonuclear neutrophils (PMNs) might play an important role in the development of multiple organ dysfunction syndromes (MODS). Somatostatin (SST) may improve the histopathological lesions as well as functions of vital organs in rats with MODS. This study was to investigate the association of SST levels in plasma or jejunum tissue and PMN life in macaques following intestinal ischemia reperfusion. SST levels in macaque plasma or jejunum tissue were significantly decreased after intestinal ischemia reperfusion (IR) injury. The apoptotic rate of PMNs was obviously reduced $(15.4 \pm 1.41$ to $3.5 \pm 0.53 \%, P<0.05)$. However, the number of peritoneal apoptotic macrophages was clearly increased. The apoptotic rate of PMNs was significantly increased $(20.0 \pm 2.24$ to $50.2 \pm 1.81 \%, P<0.01)$ after incubated with SST in vitro. Specific DNA ladder bends from PMNs were visualized with agarose electrophoresis. Specific bindings between PMNs and the antibodies for SSTR1 $(547.9 \pm 19.98 \mathrm{RU} / \mathrm{ml})$ or SSTR2 $(27.6 \pm 20.56 \mathrm{RU} / \mathrm{ml})$ were detected. The results showed physiological apoptosis of PMNs in macaques could be induced by SST through SSTRs on PMNs. The decreased SST levels in macaque plasma or jejunum tissue following intestinal ischemia-reperfusion might extend PMN life and promote the occurrence of MODS.
\end{abstract}

Key words: Polymorphonuclear neutrophils (PMNs), macrophage, apoptosis, somatostatin, macaque, multiple organ dysfunction syndromes (MODS).

\section{INTRODUCTION}

Multiple organ dysfunction syndromes (MODS) are the most serious complication following trauma and infection. It always progresses rapidly and is difficult to be restrained by organ support therapy, with high mortality rate, accounting for more than $50 \%$ of the death in intensive care unit (ICU) (Cabre et al., 2005). From the perspective of systemic inflammatory response, during the procedure of MODS, intestinal tract is not only the target organ for damage, but also the cradle and important regulator for homoiostasis and systemic inflammatory response under the stress condition. Currently, this doctrine is mainly supported by bacterial

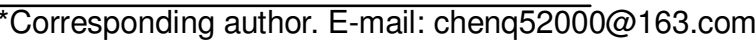

translocdtion from intetine (Nieuwenhuijzen et al., 1996). What is the regularity of innate immunity change of intestinal mucosa under such conditions as severe stress or intestinal ischemia-reperfusion? These problems have got the concerns of scholars in recent years (Saini et al., 2001; Yang and Tang, 2004).

Polymorphonuclear neutrophils (PMNs) can effectively clear the pathogenic microorganisms in organism. However, excessive activation, life extension or massive necrosis of PMNs following trauma and stress can damage tissues and cells, leading to MODS (Vavra et al., 2006; Larsson et al., 2004). Apoptotic PMNs can be cleared by macrophages. Therefore, the life cycle of macrophages is also related to the occurrence of MODS (Rinaldo et al., 1985).

As a brain-gut peptide, the effect of somatostatin (SST) 
on the immune system has gradually been recognized (Akinlolu et al., 2010). The previous study of our study group showed that SST improved the functions of various damaged organs during MODS through inhibiting mucosal mast cell degranulation, reducing the release of histamine and TNF-a and inhibiting intestinal lymphocyte homing to the gut-associated lymphoid tissue in rats with MODS (Tang et al., 2005; Yang and Tang, 2002). The problem is whether SST level in intestinal mucosa and plasma is significantly decreased following trauma and stress and weakens the containment of organism natural immunity, resulting in systemic inflammatory response? In addition, whether PMN life which is closely related to MODS is also regulated by SST is still unknown.

In our present study, the correlation between SST level and apoptosis of peripheral PMNs and peritoneal macrophages was analyzed through comparing the SST concentration before and after intestinal ischemiareperfusion. The direct effect of SST on PMN apoptosis was observed in vitro, and the potential reason of delayed PMN apoptosis during MODS was investigated in order to increase the recognition to the endogenous protection mechanism of the systemic inflammatory response and provide new ideas for the clinical treatment of MODS caused by various diseases.

\section{MATERIALS AND METHODS}

\section{Ethics statement}

All animal experiments were approved by the Administrative Committee of Experimental Animal Care and Use of Shanghai Jiao Tong University, and conformed to the National Institute of Health guidelines on the ethical use of animals.

\section{Reagents}

Percoll separating medium was purchased from Pharmacia Company, New Jersey, USA. RPMI 1640 was purchased from GIBCO Company, New York, USA. Annexin V FITC/PI was purchased from Jingmei Company, Shenzhen, China. Prolease K was purchased from Roche, Basel, Switzerland. Acridine orange and ethidium bromide were purchased from Sigma, Louisiana, USA. Bcl-2 immunohistochemistry kit was purchased from Boshide Company, Wuhan, China. Radioimmunoassay kit was purchased from EMD Millipore, Billerica, USA.

\section{Animal experiment}

3.5 to 4.5 year-old healthy macaques, weighing 4 to $8 \mathrm{~kg}$ of female and 6 to $12 \mathrm{~kg}$ of male underwent anesthesia with $10 \mathrm{mg} / \mathrm{kg}$ Ketamine and $25 \mathrm{mg} / \mathrm{kg}$ pentobarbital. 15 healthy macaques were divided into control group, ischemia-reperfusion and SST treated group, with 5 in each. Blood sample was collected via vein. Part of blood was stored at $-80^{\circ} \mathrm{C}$ for SST detection, and another part of was immediately used for PMN separation.

After anesthesia, aseptic towel was spread out on the macaque. The abdomen was cut along the abdominal midline, $2 \mathrm{~cm}$ of ileum which was $5 \mathrm{~cm}$ away from the ileocecal junction was resected, and the sample was stored at $-80^{\circ} \mathrm{C}$ for SST detection. Superior mesenteric artery was separated and clamped, and reperfusion was performed after $60 \mathrm{~min}$. Glucose, electrolyte and normal saline were continuously supplemented via vein, and necessary anesthetic agent was added. Vital signs of macaque were monitored and recorded. $24 \mathrm{~h}$ after intestinal ischemia-reperfusion, some organs such as small intestine, heart, liver, kidney, lung, brain and so on were taken out and stored for next inspection.

\section{Detection of SST in intestinal mucosa and peripheral blood}

$10 \mu \mathrm{l}$ glacial acetic acid and $2 \mathrm{ml}$ acetone were added into $100 \mu \mathrm{l}$ intestinal mucosa tissue homogenate and peripheral serum. The mixture was centrifuged at $600 \times \mathrm{g}$ at $4^{\circ} \mathrm{C}$ for $15 \mathrm{~min}$. $1 \mathrm{ml}$ acetone was added into the supernatant, and then centrifuged at $600 \times \mathrm{g}$ at $4^{\circ} \mathrm{C}$ for $15 \mathrm{~min}$. The concentration of SST in intestinal mucosa and peripheral blood was detected by radioimmunoassay.

\section{Cell separation} PMN isolation and purification with Percoll discontinuous
density gradient centrifugation

Density gradient was constituted by the bottom $5 \mathrm{ml} 72 \%$ Percoll and the upper $5 \mathrm{ml} \mathrm{63 \%} \mathrm{Percoll.} \mathrm{Before} \mathrm{and} \mathrm{2,} \mathrm{6,} 24 \mathrm{~h}$ after clamping, $5 \mathrm{ml}$ heparin-anticoagulated peripheral vein blood sample was collected from healthy macaque. The anticoagulated blood was placed in the Percoll separation solution and centrifuged at $600 \times \mathrm{g}$ for $20 \mathrm{~min}$. The remaining red blood cells were dissolved with isotonic ammonium chloride solution $\left(\mathrm{NH}_{4} \mathrm{Cl} 155 \mathrm{mmol} / \mathrm{L}, \mathrm{KHCO}_{3}\right.$ $10 \mathrm{mmol} / \mathrm{L}$, EDTA $0.1 \mathrm{mmol} / \mathrm{L}$ ), and then washed with Hanks solution twice. Cells were suspended in RPMI 1640 containing with $10 \%$ fetal calf serum. Cell morphology was observed under microscope. Cell activity was detected with trypan blue staining, and the cell number was adjusted to $5 \times 10^{5} / \mathrm{ml}$.

\section{Isolation and collection of peritoneal macrophages}

Intraperitoneal irrigation was performed in healthy macaques with $500 \mathrm{ml}$ RPMI 1640 medium via intraperitoneal injection before and after clamping superior mesenteric artery. The irrigating solution was collected and centrifuged at $400 \times \mathrm{g}$ for $5 \mathrm{~min}$. Peritoneal macrophages of $90 \%$ purity were obtained. Cell morphology was observed under microscope. Cell activity was detected with trypan blue, and cell number was adjusted to $5 \times 10^{5} / \mathrm{ml}$.

\section{Effect of SST on PMNs in vitro}

In the experiment groups, SST was added into isolated PMN, with final concentrations of $5 \times 10^{-5}, 5 \times 10^{-6}$ and $5 \times 10^{-7} \mathrm{~mol} / \mathrm{L}$. In the control group, normal saline was added into isolated PMN. The mixture was incubated at 37 centrifuged at $400^{\circ} \mathrm{C}$ for 30 min with $5 \% \mathrm{CO}_{2}$.

\section{Detection of cell apoptosis rate by flow cytometry}

Peripheral PMNs and peritoneal macrophages before and 2, 6, $24 \mathrm{~h}$ after clamping the superior mesenteric artery were collected. PMNs and macrophages were washed with PBS twice and centrifuged. The supernatant was removed. $100 \mu \mathrm{l}$ buffer, $5 \mu \mathrm{l}$ Annexin $\mathrm{V}$ and 10 $\mu \mathrm{l}$ propidium iodide $(\mathrm{PI})$ were added into cells and incubated at room temperature for $15 \mathrm{~min}$, avoiding light for $15 \mathrm{~min} .400 \mu \mathrm{l}$ PBS was added into cells for next detection. 
Table 1. SST content in small intestinal mucosa homogenate and peripheral blood.

\begin{tabular}{lcc}
\hline & SST in small intestinal mucosa $(\mathrm{ng} / \mathbf{m g})$ & SST in peripheral blood (pg/ml) \\
\hline Before clamping & $256.41 \pm 7.98$ & $160.61 \pm 33.84$ \\
Intestine ischemia reperfusion injury & $179.83 \pm 44.50^{*}$ & $62.17 \pm 13.56^{*}$ \\
\hline
\end{tabular}

$\mathrm{N}=5$; ${ }^{*}$ vs. before clamping; $P<0.01$.

Table 2. Apoptosis rate of PMNs during MODS.

\begin{tabular}{lcc}
\hline & Apoptosis rate of PMNs (\%) & Apoptosis rate of peritoneal macrophages (\%) \\
\hline Before clamping & $15.4 \pm 1.41$ & $14.1 \pm 1.66$ \\
2 h after clamping & $11.0 \pm 1.02^{\star}$ & \\
6 h after clamping & $7.1 \pm 0.54^{*}$ & $20.2 \pm 1.80^{\star}$ \\
24 h after clamping & $3.5 \pm 0.53^{* *}$ & \\
\hline
\end{tabular}

$\mathrm{N}=5$, vs. before clamping; ${ }^{*} P<0.05 ;{ }^{* *} P<0.05$.

\section{Detection of Bcl-2 by immunohistochemistry}

Anticoagulated blood was separated with Percoll. After centrifugation, PMNs were used for film preparation and paraformaldehydefixed for 30 min. $\mathrm{H}_{2} \mathrm{O}_{2}$ was added to remove the inactivated endogenous enzymes at room temperature for $10 \mathrm{~min}$. The section was washed with distilled water 3 times and then incubated with $5 \%$ BSA Blocking solution for $20 \mathrm{~min}$ at room temperature. Then the section was incubated with rabbit anti-human Bcl-2 antibody for $1 \mathrm{~h}$ at $37^{\circ} \mathrm{C}$ and then washed with PBS (pH7.4) for 2 min, 3 times. Then the section was incubated with goat anti-rabbit lgG for $20 \mathrm{~min}$ at $37^{\circ} \mathrm{C}$ and then washed with PBS (pH7.4) for 2 min, 3 times. Then the section was incubated with $\mathrm{SABC}$ for $20 \mathrm{~min}$ at $37^{\circ} \mathrm{C}$ and then washed with PBS (pH7.4) for 5 min, 4 times. The DAB coloration was performed with $D A B$ Kit. The proper mixture of 1 drop of $A, B$ and $C$ reagent plus $1 \mathrm{ml}$ distilled water was added on the section for coloration at room temperature. The reaction time was controlled under microscope, usually for $20 \mathrm{~min}$. The section was washed with the distilled water. The section was slightly re-stained with hematoxylin, followed by dehydration, sealing, and observation under microscopic. The brown granules in cytoplasm and nucleus indicated positive staining.

Detection of SST receptor on PMNs with biomolecular interaction system

The isolated and purified PMNs $\left(1 \times 10^{4}\right.$ cells $\left./ \mathrm{ml}\right)$ by Percoll discontinuous density gradient centrifugation were centrifuged, and $100 \mu \mathrm{l}$ specific protein extraction buffer HBS-EP (10 mM HEPES, $150 \mathrm{mM} \mathrm{NaCl}, 0.005 \%$ Surfactant P20, 3 mM EDTA, pH 7.4) for biomolecular interaction systems (Biacore $X$, Amersham Biosciences Ltd., Uppsala, Sweden) was added into the cells. Cells were broken by using ultrasonication, and then centrifuged at $10000 \times \mathrm{g}$ at low temperature $\left(4^{\circ} \mathrm{C}\right)$ for $15 \mathrm{~min}$. The supernatant was collected and stored at $-80^{\circ} \mathrm{C}$ for the next detection.

Two SST receptor antibodies (SSTR-1 and SSTR-2 antibody) were injected into the biomolecular interaction system specific $\mathrm{CM}-5$ blank chip at $20 \mu \mathrm{g} / \mathrm{ml}$ concentration by amino-coupling method, and the binding site on the chip surface was combined with SSTR-1 or SSTR-2 antibody at the maximum. $60 \mu \mathrm{l}$ PMN protein sample solution was added into the sample hole, with the protein extraction buffer as the blank control. The detection was performed according to the procedure of binding-binding/dissociation-elution-surface regeneration within biomolecular interaction system. The binding capacity of each sample (resonance units, RU value) was analyzed with specific software (BIAevaluation, Amersham Biosciences Ltd., Uppsala, Sweden). Specific binding = total binding - non-specific binding. The unit of both SSTR-1 volume and SSTR-2 volume was $\mathrm{RU} / \mathrm{ml}$.

\section{Statistical analysis}

All data were expressed by means \pm standard deviation $(X \pm$ $\mathrm{SD})$. Analysis of variance and t-test was adopted for statistical analysis. $P<0.05$ was considered statistically significant.

\section{RESULTS}

\section{Detection of SST content in macaque intestinal mucosa and peripheral blood}

Compared with the normal control, SST content in macaque intestinal mucosa and peripheral blood following intestinal ischemia-reperfusion was significantly decreased (Table 1, $P<0.01$ ).

\section{Changes of apoptosis rate of PMNs and peritoneal macrophages}

Flow cytometry assay showed that the apoptosis rate of macaque peripheral PMNs was decreased 2, 6 and $24 \mathrm{~h}$ after clamping the superior mesenteric artery as compared with those before clamping (Table 2). The apoptosis rate reduced to $3.5 \pm 0.53$ from $15.4 \pm 1.41 \%$ before clamping $(P<0.05)$. In contrast, the apoptosis rate of macaque peritoneal macrophages was significantly increased following intestine ischemia-reperfusion (Table 2) $(P<0.05)$. 


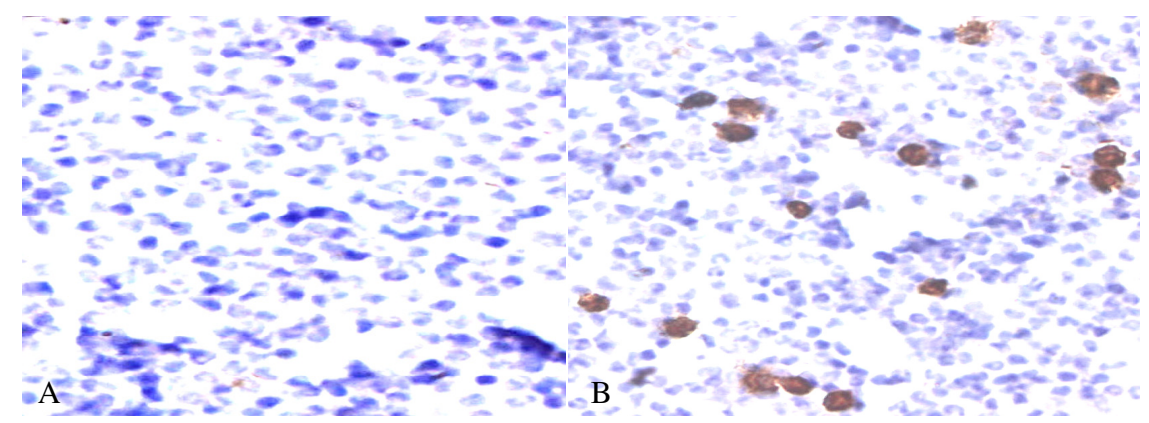

Figure 1. Immunohistochemical staining of $\mathrm{Bcl}-2$ in $\mathrm{PMNs}$ (SABC staining-100x) $\mathrm{A}$ : Normal control; B: After intestine ischemia-reperfusion.

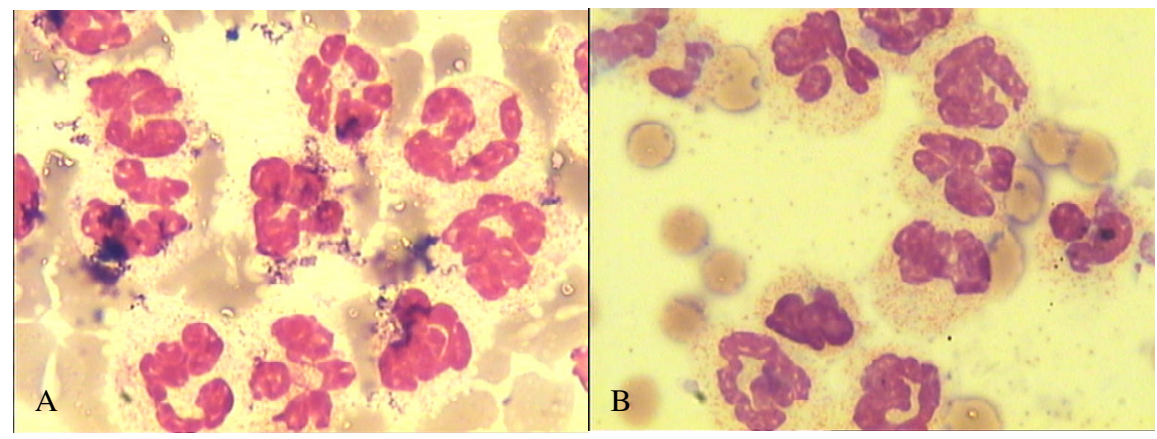

Figure 2. PMNs in macaque peripheral blood (Wright's staining 1000x). A: Control; B: After SST treatment.

\section{Immunohistochemical staining of Bcl-2}

After intestine ischemia reperfusion, PMN cells were brown, and $\mathrm{Bcl}-2$ positive particles were significantly increased (Figure 1).

\section{Effect of SST on PMN apoptosis in vitro}

\section{Morphological changes of PMNs}

After SST $\left(5 \times 10^{-5} \mathrm{~mol} / \mathrm{L}\right)$ treatment on macaque peripheral PMNs, cell apoptosis was increased as compared with the control group. Under the common microscope, the whole cells can be displayed by Wright's staining. The apoptotic PMN cells shrinked, with concentrated, high-density and high-acidophily cytoplasm and small nuclei accompanied with karyopyknosis, chromatic agglutination karyorrhexis (Figure 2). Normal PMN was larger, with integrity nuclear membrane and cell membrane, pale cytoplasm, and large nuclei, and the structure was normal.

Under the condition of double fluorescent staining of acridine orange and ethidium bromide, the apoptotic PMNs showed shrinked, with concentrated cytoplasm and small nucleus accompanied with karyopyknosis, chromatic agglutination under fluorescence microscope.
The apoptotic cells were orange-red, while the normal cells were green, with normal nuclear structure, (Figure 3, arrows).

\section{Effect of SST on the ultrastructure of PMNs in vitro}

Transmission electron microscopy revealed that the electron density of cytoplasm and nucleus was increased after SST treatment. The cells were shrinked with wrinkled folds and curve on the cell membrane, forming bud-like protuberances on the surface of the membrane, known as budding. Cytoplasm condensed, and the density of cytoplasm and organelles increased. The organelles were compressed, with nuclear chromatin condensation gathering under the nuclear membrane, known as chromatin margination, and the nuclear showed karyopyknosis. PMN without SST treatment had larger volume, with integrated nuclear membrane and cell membrane, lightly stained cytoplasm, loose organelles, large, and the structure was normal (Figure 4).

\section{Apoptosis rate of PMN detected by flow cytometry}

After SST treatment in vitro, the apoptosis rate of PMNs was $50.2 \pm 1.81 \%$, which was significantly increased as 


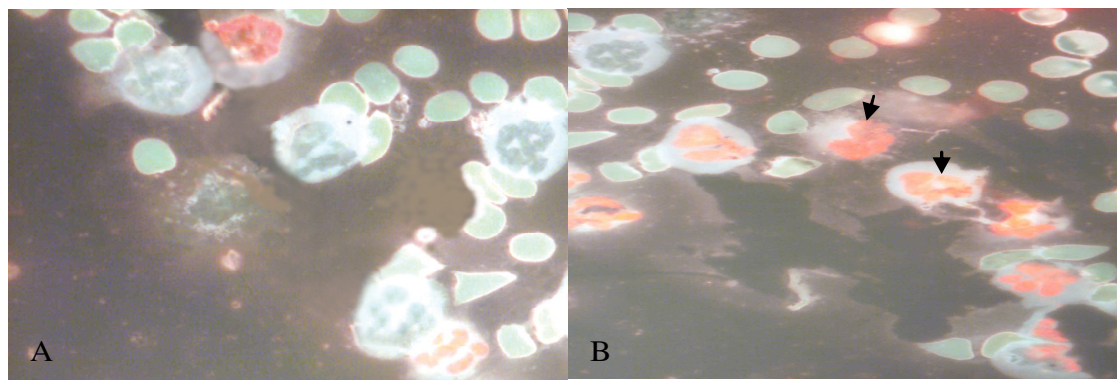

Figure 3. PMNs in macaque peripheral blood (fluorescein staining with acridine orange and ethidium bromide 1000x). A: Control; B: After SST treatment.

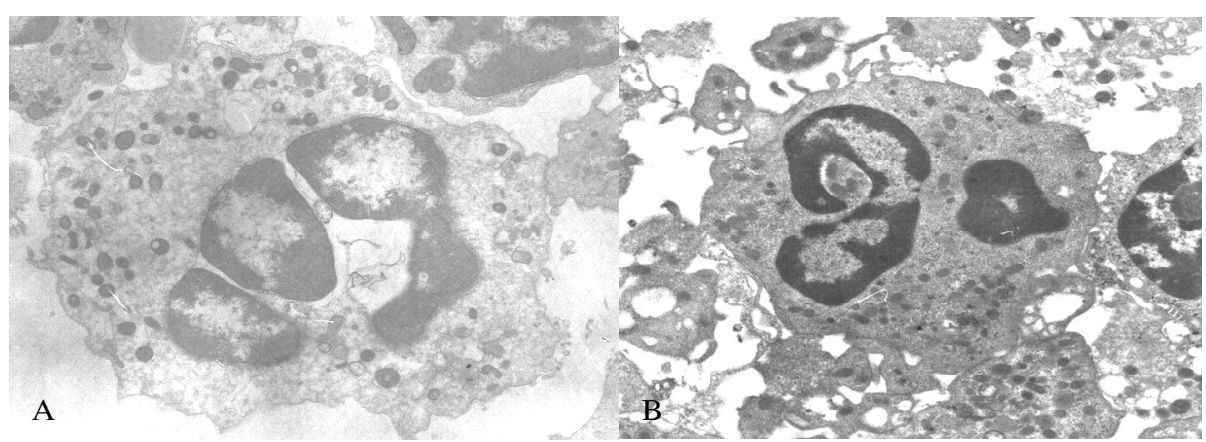

Figure 4. $P M N$ s in macaque peripheral blood (transmission electron microscope 10,000x). A: Control; B: After SST treatment.

Table 3. Effect of different concentrations of SST on the apoptosis rate of PMNs.

\begin{tabular}{lc}
\hline & Apoptosis rate (\%) \\
\hline Control group & $20.0 \pm 2.24$ \\
SST $\left(5 \times 10^{-7} \mathrm{~mol} / \mathrm{L}\right)$ & $27.8 \pm 2.61$ \\
SST $\left(5 \times 10^{-6} \mathrm{~mol} / \mathrm{L}\right)$ & $40.4 \pm 3.23^{\star}$ \\
SST $\left(5 \times 10^{-5} \mathrm{~mol} / \mathrm{L}\right)$ & $50.2 \pm 1.81^{\star}$ \\
\hline
\end{tabular}

${ }^{*}$ vs. the control group, $P<0.01$

compared with the control group $(20.0 \pm 2.24 \%)(P<0.01)$. Moreover, with the increase of SST concentration, the apoptosis inducement was also increased. SST concentration was positively correlated with the apoptosis of PMNs, and the correlation coefficient was 0.830 (Table 3).

\section{Gel electrophoresis analysis for DNA fragments of PMNs}

DNA of the apoptotic cells was cut off at the site between nucleosomes and degraded into 180 to $200 \mathrm{bp}$ or their whole multiples oligonucleotide due to the endogenous endonuclease activation. After $5 \times 10^{-5} \mathrm{~mol} / \mathrm{L}$ SST treatment to PMNs, the obvious DNA Ladder appeared through agarose gel electrophoresis and ethidium bromide staining, whereas the control PMN did not show DNA ladder (Figure 5).

\section{Detection of SST receptor (SSTR)}

Biomolecular interaction assay showed that PMNs could combine with the SSTR-1 and SSTR-2 antibodies coupling in the CM-5 chip (Figure 6). The specific combine weight of SSTR-1 and SSTR-2 were 547.9 \pm 19.98 and $27.6 \pm 20.56 \mathrm{RU} / \mathrm{ml}$, respectively.

\section{Status of important organs of macaques $24 \mathrm{~h}$ after intestinal ischemia-reperfusion}

$24 \mathrm{~h}$ after intestinal ischemia-reperfusion, all the macaques 


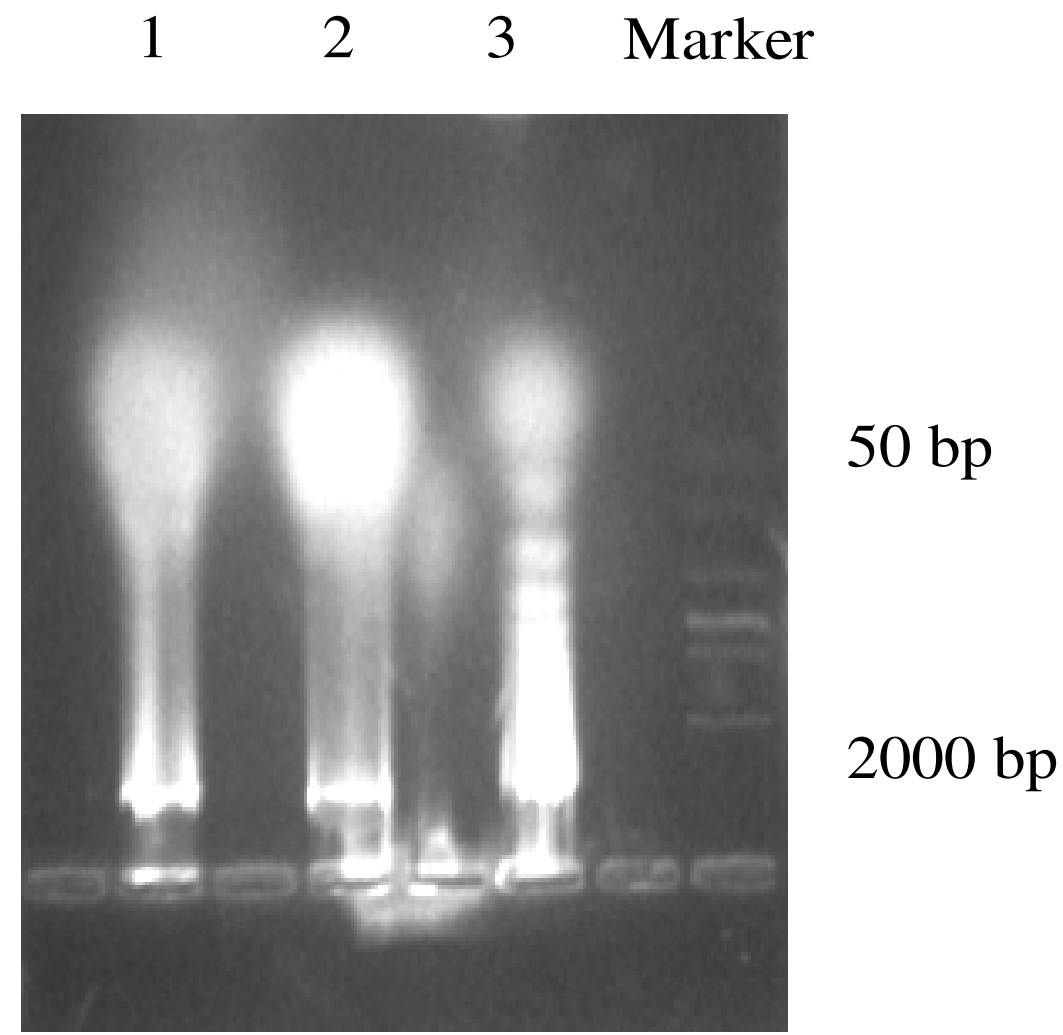

Figure 5. DNA electrophoresis of macaque peripheral blood. 1 and 2 represent the control group; 3 represent the experiment group; Marker represents the standard molecular weight.

presented MODS. Various degrees of inflammatory injury also appeared in some important organs such as intestine, lung, liver and kidney and so on.

\section{DISCUSSION}

Ischemia-reperfusion injury is considered as a basic link of MODS after trauma and stress, and the loss control of inflammation is the most important pathophysiological process. Intestinal tract is the starting organ of MODS. PMNs are derived from hematopoietic stem cells in bone marrow. PMNs differentiate and mature in bone marrow. When infection, trauma or inflammatory reaction occurs, PMNs cross the blood vessel endothelium and enter the local tissue, thereby exerting a series of biological effects. PMNs released from bone marrow to peripheral blood are inactive, with half-life of only 4 to $10 \mathrm{~h}$. If PMNs cross blood vessel endothelium and enter tissue, they may survive for 1 to 2 days. Under physiological condition, the senile PMNs are recognized and cleared by macrophages mainly through apoptosis. Moreover, they do not release enzymes, and also not produce cell debris and inflammatory mediators. This is the important mechanism for avoiding tissue damage and promoting inflammation absorption (Yan et al., 2005). Our result showed that
PMN apoptosis rate in macaque peripheral blood after intestinal ischemia-reperfusion decreased to $1 / 5$ of the PMN apoptosis rate before intestinal ischemiareperfusion. Correspondingly, the apoptosis rate of macrophages was significantly increased. The integrated result is the extending of the PMN life. When PMNs undergo necrosis, the cell membrane will be ruptured, and the cell contents will leaked out, with the release of a large quantity of enzymes, inflammatory product and cytokines, which will be of benefit to the removal of pathogens. However, excessive PMN necrosis can cause more inflammatory cells to involve in inflammatory reaction, aggravating tissue damage (Koenig et al., 2005). In our study, all macaques suffered from MODS. It is coincided with the previous study in human, that is, PMN apoptosis in both MODS and adult respiratory distress syndrome is significantly delayed as compared with normal persons (Tamura et al., 2008).

As we know, most cytokines such as IL-1, IL-2, IL-8, IL15, IL-4, IL-6, G-CSF and GM-CSF can inhibit PMN apoptosis, while others factors such as TNF, FasL and IL10 show the contrary effects, causing or promoting PMN apoptosis (Biffl et al., 1999; Spangelo et al., 2007). Bacterial endotoxin can cause PMN initialization and also inhibit PMN apoptosis simultaneously (Wessely-Szponder et al., 2008). Glucocorticoid drugs such as 
A

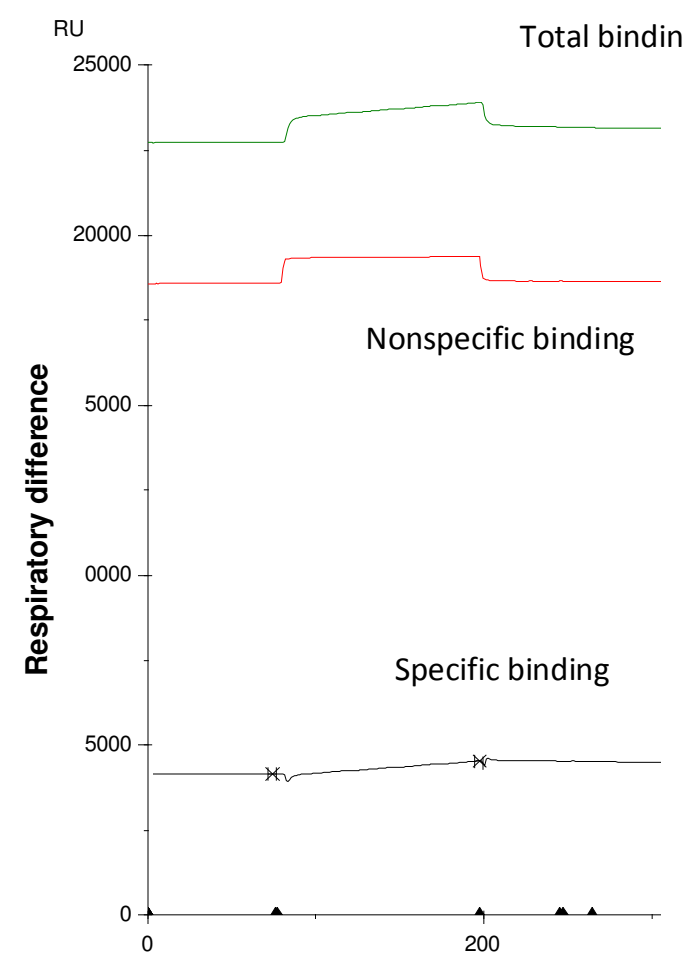

B

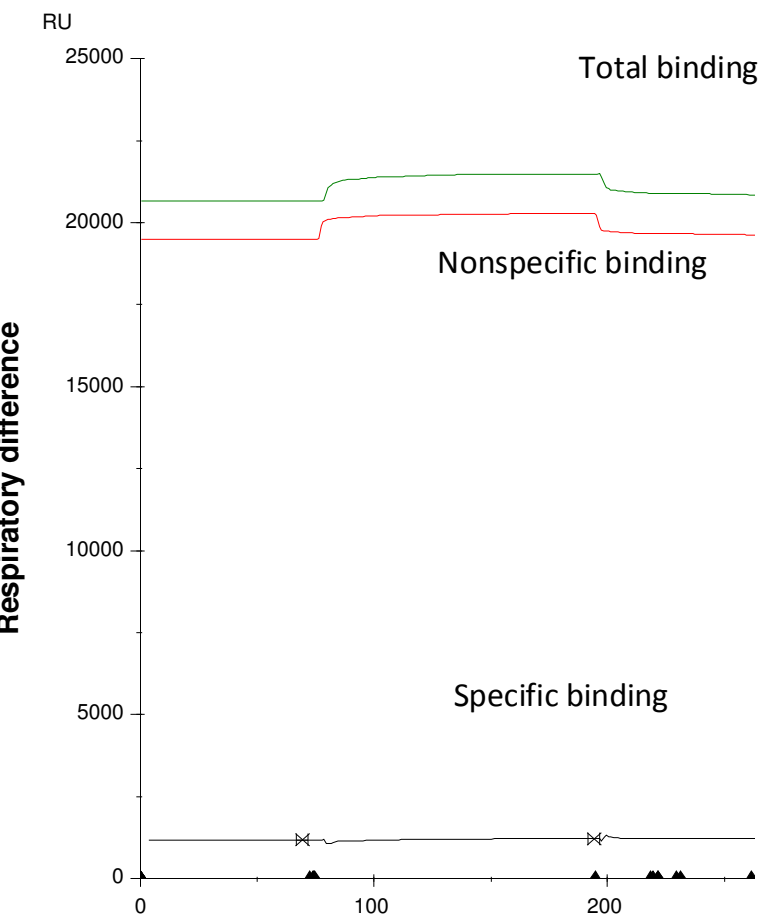

Figure 6. PMNs expressed SST receptor (the primary curve of biomolecular interaction system). A: SSTR-1; B: SSTR-2.

dexamethasone, methylprednisolone and hydrocortisone have the inhibitory role on the apoptosis of adult PMNs, with a dose dependent manner (Lamote et al., 2008). Intestinal tract is the most important place for the cross talking of immunity-nerve-endocrine (Ding et al., 2010). SST which is secreted from intestinal D-cells is the important regulatory peptide in the mucosal immune micro-environment. However, so far, it is still not gotten the attention that whether this important anti-inflammatory peptides can affect PMN apoptosis or not. In our study, we observed through multiple morphology methods that SST-treated PMNs had unique morphological and biochemical changes, such as cell shrinkage, chromatin condensation as well as margination, and DNA breakage and so on, suggesting that SST could directly induce PMN apoptosis. The characteristic DNA ladder results further indicated that SST positively promoted PMN apoptosis. Biomolecule interaction system indicated that PMN expressed SSTR, which supplied molecular targets for the direct effects above.

Simultaneously, we also observed that SST could significantly inhibit macrophage apoptosis both from morphology and flow cytometry assay after the coincubation of macrophages and SST, which would be conducive to the phagocytosis of apoptotic PMNs by macrophages. PMNs will undergo necrosis, if the apoptotic PMNs are excessive, or the apoptotic PMNs can not be cleared in time due to various reasons, or the monocyte-derived macrophages are not mature enough and can not timely digest the apoptotic PMNs, or the recognition of macrophages for the apoptotic PMNs is disordered.

Under physiological condition, SST in peripheral blood and intestinal mucosa may be one of the important factors which promote PMN apoptosis in organism. In our study, before and after intestinal ischemia-reperfusion, SST concentrations in the small intestinal mucosa and peripheral blood were decreased by 30 and $61 \%$, respectively. As a result, the factors that promoted PMN apoptosis in vitro were reduced. The life of PMN was extended, and the necrosis was increased. The aggravated intestinal mucosa tissue damage and loss control of inflammation finally cause MODS.

In conclusion, under physiological conditions, SST induces cell apoptosis and maintains the appropriate inflammatory response through the corresponding receptors on PMNs. Intestinal ischemia-reperfusion injure reduces SST level of small intestinal mucosa or peripheral blood, which damages the endogenous physical protection mechanism and causes the extended PMN life and aggravated damage, thus promoting the systemic inflammatory response syndrome and MODS. Because these conclusions are derived from the primate-macaque which is close to human, this enhances the understanding for human PMN physiology and inflammatory pathophysiology, and benefits to selection of clinical 
therapeutics for systemic inflammatory diseases.

\section{ACKNOWLEDGMENT}

The present study is supported by the key grant of Nature Science Fund of China (No. 30330270).

\section{REFERENCES}

Akinlolu O, Ottolino-Perry K, McCart JA, Reilly RM (2010). Antiproliferative effects of $111 \mathrm{ln}$ - or $177 \mathrm{Lu}-\mathrm{DOTATOC}$ on cells exposed to low multiplicity-of-infection double-deleted vaccinia virus encoding somatostatin subtype-2 receptor. Cancer. Biother. Radiopharm., 25(3): 325-333.

Biffl WL, Moore EE, Zallen G, Johnson JL, Gabriel J, Offner PJ (1999). Silliman CCNeutrophils are primed for cytotoxicity and resist apoptosis in injured patients at risk for multiple organ failure. Surgery, 126: 198-202.

Cabre L, Mancebo J, Solsona JF, Saura P, Gich I, Blanch L, Carrasco G, Martin MC; and the Bioethics Working Group of the SEMICYUC (2005). Multicenter study of the multiple organ dysfunction syndrome in intensive care units: the usefulness of Sequential Organ Failure Assessment scores in decision making. Intensive. Care. Med., 31: 927-933.

Ding Y, Lv B, Meng LN, Fan YH, Guo Y, Shen Y, Chen S (2010). Proteomic expression analysis of colonic mucosa in a rat model of irritable bowel syndrome. Chin. Med. J., 2: 90(8): 564-569. Chinese.

Koenig JM, Stegner JJ, Schmeck AC, Saxonhouse MA, Kenigsberg LE (2005). Neonatal neutrophils with prolonged survival exhibit enhanced inflammatory and cytotoxic responsiveness. Pediatr. Res., 57: 424-429.

Larsson J, Persson C, Tengvall P, Lundqvist-Gustafsson H (2004). Antiinflammatory effects of a titanium-peroxy gel: role of oxygen metabolites and apoptosis. J. Biomed. Mater. Res. A., 68: 448-457.

Lamote I, Meyer E, Duchateau L, Burvenich C (2008). Influence of 17beta-estradiol, progesterone, and dexamethasone on diapedesis and viability of bovine blood polymorphonuclear leukocytes. J. Dairy. Sci., 87: 3340-3349.
Nieuwenhuijzen GA, Deitch EA, Goris RJ (1996).The relationship between gut-derived bacteria and the development of the multiple organ dysfunction syndrome. J. Anat., 189: 537-548.

Rinaldo JE, Henson JE, Dauber JH, Henson PM (1985). Role of alveolar macrophages in endotoxin-induced neutrophilic alveolitis in rats. Tissue. Cell., 17: 461-472.

Saini MS, Liberati DM, Diebel LN (2001). Sequential changes in mucosal immunity after hemorrhagic shock. Am. Surg., 67: 797-801.

Spangelo BL, Horrell S, Goodwin AL, Shroff S, Jarvis WD (2007). Somatostatin and gamma-aminobutyric acid inhibit interleukin-1 betastimulated release of interleukin-6 from rat C6 glioma cells. Neuroimmunomodulation, 11: 332-340.

Tamura DY, Moore EE, Partrick DA, Johnson JL, Offner PJ, Silliman CC (2008). Acute hypoxemia in humans enhances the neutrophil inflammatory response. Shock, 17: 269-273.

Tang C, Lan C, Wang C, Liu R (2005). Amelioration of the development of multiple organ dysfunction syndrome by somatostatin via suppression of intestinal mucosal mast cells. Shock, 23: 470-475.

Vavra AK, Laurent CJ, Ngo V, Sweeney JF, Levitt JM (2006). Sulfur mustard primes phagocytosis and degranulation in human polymorphonuclear leukocytes. Int. Immunopharmacol., 4: 437-445.

Wessely-Szponder J, Urban-Chmiel R, Wernicki A, Bobowiec R (2008). Effect of leukotoxin of Mannheimia haemolytica and LPS of E. coli on secretory response of bovine neutrophils in vitro. Pol. J. Vet. Sci., 8: 99-105.

Yan SR, Bortolussi R, Issekutz TB, Issekutz AC (2005). Increased chemoattractant induced neutrophil oxidative burst, accelerated apoptosis, and dysregulated tyrosine phosphorylation associated with lifelong bacterial infections. Clin. Immunol., 117: 36-47.

Yang H, Tang CW (2002). Vasoactive Intestinal Peptide or Somatostatin Inhibits Homing of Intestinal CD8 + Lymphocytes in Rats. Shanghai. J. Immunol., 22: 182-185.

Yang H, Tang CW (2004). Changes of intestinal mucosal lymphocyte homing in rats with multiple organ dysfunction syndrome. Chin. Critical. Care. Med., 16: 333-337. 